\title{
Can judgments according to case fatality rate be correct all the time during epidemics? Estimated cases based on CFR in different scenarios and some lessons from early case fatality rate of coronavirus disease 2019 in Iran
}

\author{
Ghobad Moradi ${ }^{1}$, Bakhtiar Piroozi*1®${ }^{1}$, Amjad Mohamadi-Bolbanabad ${ }^{1}$, Hossein Safari $^{2}$, Azad Shokri $^{1}$, Ramyar Rahimi $^{3}$
}

Received: 27 Mar 2020

Published: 29 Mar 2020

\begin{abstract}
Background: The new Coronavirus disease (COVID-19) was first identified in China in 2019. Case fatality rate (CFR) indicator of the disease is one of the most important indices noticed by experts, policymakers, and managers, based on which daily evaluations and many judgments are made. CFR can change during epidemics. This study aimed to estimate the actual number of COVID-19 cases in Iran and to calculate the early CFR for the disease based on official statistics.

Methods: This was a descriptive study whose data were obtained from the website of the Ministry of Health and Medical Education of Iran from February 20, 2020 until March 26, 2020. CFR has been obtained by dividing the total number of deaths by the total number of confirmed cases at one point in time. In this study, the actual number of COVID-19 cases in Iran was estimated based on the mortality model in 4 scenarios. Excel 2013 software was used to analyze the data.

Results: According to the findings of this study, In Iran, until March 26, 2020, a total of 27017 people have been infected by COVID-19 and 2077 died of it. However, CFR indicator had a descending trend in Iran: $100 \%, 18.6 \%, 8.8 \%, 3.3 \%, 6.9 \%$, and $7.7 \%$ on days 1, 5, 10, 20,30, and 35, respectively. The actual number of COVID-19 cases in Iran was estimated to be 4789454,2873673 , 1436 836, and 718418 as of March 26, 2020 according to the 4 scenarios, respectively.

Conclusion: In emerging epidemics, CFR indicator must not be used as a basis to judge the performance of a health system unless that epidemic condition has been clarified. Moreover, it is suggested that in the outbreak of an epidemic, specifically emerging diseases, CFR must not be the base of judgment. Making judgments, specifically in the outbreak of emerging epidemics, based on fatality rate can lead to information bias. It is also possible to estimate the total number of patients based on the CFR in circumstances where little information is available on the disease.
\end{abstract}

Keywords: Coronavirus, COVID-19, Case fatality rates, Pandemic, Mortality estimated model, Iran

Conflicts of Interest: None declared

Funding: Kurdistan University of Medical Sciences

*This work has been published under CC BY-NC-SA 1.0 license.

Copyright $\odot$ Iran University of Medical Sciences

Cite this article as: Moradi Gh, Piroozi B, Mohamadi-Bolbanabad A, Safari H, Shokri A, Rahimi R. Can judgments according to case fatality rate be correct all the time during epidemics? Estimated cases based on CFR in different scenarios and some lessons from early case fatality rate of coronavirus disease 2019 in Iran. Med J Islam Repub Iran. 2020 (29 Mar);34:26. https://doi.org/10.47176/mjiri.34.26

\section{Introduction}

Coronaviruses are a large family of viruses, and some of

them cause diseases in humans and some others in animals

Corresponding author: Dr Bakhtiar Piroozi, bpiroozi@gmail.com

$$
\text { b.piroozi@muk.ac.ir }
$$

1. Social Determinants of Health Research Center, Research Institute for Health Development, Kurdistan University of Medical Sciences, Sanandaj, Iran

2. Health Promotion Research Center, Iran University of Medical Science, Tehran, Iran

3. Student Research Committee, Kurdistan University of Medical Sciences, Sanandaj, Iran $\uparrow$ What is "already known” in this topic:

The present study is the first study to investigate the case fatality rate (CFR) in Iranian Covid-19, and estimated case of this disease based on CFR in different scenarios.

\section{$\rightarrow$ What this article adds:}

The present study investigate trend of CFR based on reported Covid-19 in the Iran, and we notice that in emerging epidemics, CFR indicator must not be used as a basis to judge a health system's performance until that epidemics condition has not been clarified. Also in this study, the actual number of COVID-19 cases in Iran was estimated based on the mortality model. 
such as bats and camels. Human coronaviruses typically cause mild diseases. Sometimes, animal coronaviruses evolve and spread among humans and cause severe diseases, such as severe acute respiratory syndrome (SARS) in 2002 and Middle East respiratory syndrome (MERS) in 2012 (1-3). A new species of this virus is 2019-Novel Coronavirus [severe acute respiratory syndrome co ronavirus (SARS-CoV)-2], COVID-19, which had not been previously identified in humans. This virus was first identified in city of Wuhan in China in December 2019. This virus had a more widespread outbreak in China and positive cases of this disease were reported in more than 160 countries until March 26, 2020 (1, 4). According to the published world statistics, the number of identified people infected with coronavirus was 460611 until March 26, 2020, of whom 113798 recovered and 20842 died. The reported fatality rate of this disease has been $2.4 \%$ to date. According to the existing evidences, the emergence of this disease is mild in almost $96 \%$ of people and is serious or critical in $4 \%(5)$.

In Iran, the first positive case of COVID-19 was confirmed in February 20, 2020 in city of Qom and until March 26, 2020, the total number of cases in the country reached 27017 . Of the total number of patients, 9625 recovered and 2077 died (6). According to global statistics, to date, Iran has reported the most positive cases of coronavirus after China, Italy, USA, Spain, and Germany (5).

One of the most important indices noticed by health care experts, policymakers, and managers in epidemics, specifically in emerging epidemics, is CFR indicator, which is obtained by dividing the total number of deaths by the total number of confirmed cases at one point in time. In most cases, this indicator is utilized for specific epidemics of acute diseases such as cholera during which all patients are under treatment in a specific period of time and this makes it possible to calculate the death toll caused by a disease. The CFR indicates the fatality potential of a disease and it just includes the proportion of death toll to the number of patients. This indicator can be used for the following purposes: to describe fatality trend and its general changes; (1) to make decisions for health care priorities, resource allocation, planning intervention programs, and evaluation; and (2) to refine plans to improve public health; however, CFR can terrify a society in case of emerging epidemics when it is reported high $(7,8)$. The exact value of CFR in the early stages of the epidemic is unknown and its precise estimation is impossible. At the beginning of epidemics, the number of actual cases exposed is largely underestimated (9). Therefore, current estimates of CFR for COVID-19 should also be interpreted with caution as the disease is currently unknown. In Iran and in many other countries, some interpretations were made based on CFR during or in the middle of COVID-19 outbreak. These interpretations were sometimes published on social news networks and caused fear among people and put pressure on countries' health system. In Iran, given the fact that in this outbreak, CFR was high, there were different interpretations on the fatality rate of this disease, based on which different judgments were made concerning the health system. This study aimed to estimate the actual number of COVID-19 cases in Iran and to calculate the early CFR (not the actual CFR value) based on published official statistics. This study also aimed to answer the question of whether epidemics are best judged by the CFR indicator at each stage.

\section{Methods}

This was a descriptive study whose required data were obtained from the website of the Ministry of Health and Medical Education of Iran and that of Worldmeter from February 20, 2020 until March 26, 2020 (6, 5). Data were published daily. CFR was obtained by dividing the total number of deaths by the total number of confirmed cases at one point in time (8) (Formula 1).

\section{Equation (1): \\ Case Fatality Rate $=\frac{\text { Total confirmed death from COVID-19 }}{\text { Total confirmed cases of COVID-19 }}$}

In this study, the actual number of COVID-19 cases in Iran was estimated based on the mortality model, details of which are provided in Tomas Pueyo's article (10). This estimate was based on the following assumptions:

1. In 4 scenarios, CFR was considered to be $0.3 \%$, $0.5 \%, 1 \%$, and $2 \%$.

2. The mean interval between the person being infected with the virus and the person's death was 17.3 days on average.

3. The average doubling time of infected cases was 6.2 days.

For example, under the third scenario, 1 death in one day means almost 692 actual cases in that day.

Given that the number of deaths is considered to be the peak of the disease, which is not usually underestimated, we think that it is better to calculate CFR based on different scenarios of best estimates of asymptomatic cases not referring to hospitals. Thus, based on the number of deaths, we estimated the total number of patients in several scenarios. Excel 2013 was used to analyze the data.

\section{Results}

As demonstrated in Table 1, until March 26, 2020, the total number of the identified infected patients was 27017 in Iran, of whom 9625 recovered and 2077 died. This table shows the number of the identified cases since the outbreak and the number of perished people on different days. The indicator of CFR has had a descending trend such that the amount of this indicator on day 1, 5, 10, 20, 30 , and 35 was $100 \%, 18.6 \%, 8.8 \%, 3.3 \%, 6.9 \%$ and $7.7 \%$, respectively.

Based on the first, second, third, and fourth scenarios, the actual number of COVID-19 cases on March 26, 2020 in Iran was estimated to be 4789 454, 2873 673, 1436 836, and 718418 , respectively (Table 1 ).

Figure 1 presents the time course of the number of people infected by COVID-19 its CFR based on confirmed cases in Iran.

Figure 2 shows the time course of official and definitive number of COVID-19 cases in Iran based on 4 scenarios. 
Gh. Moradi, et al.

\begin{tabular}{|c|c|c|c|c|c|c|c|c|c|}
\hline ID & Date & $\begin{array}{c}\text { Confirmed } \\
\text { Cases }\end{array}$ & $\begin{array}{l}\text { Confirmed } \\
\text { Deaths }\end{array}$ & Recovered & $\begin{array}{c}\text { Case Fatality Rate: } \\
\text { Confirmed Deaths/ } \\
\text { Confirmed Cases } \\
\text { (Reported cases) }\end{array}$ & $\begin{array}{c}\text { Scenario } 1 . \\
\text { Estimated Cases } \\
\text { based on first } \\
\text { scenario } \\
(\mathrm{CFR}=0.3 \%)\end{array}$ & $\begin{array}{c}\text { Scenario } 2 . \\
\text { Estimated Cases } \\
\text { based on second } \\
\text { scenario } \\
(\mathrm{CFR}=0.5 \%)\end{array}$ & $\begin{array}{c}\text { Scenario } 3 . \\
\text { Estimated Cases } \\
\text { based on third } \\
\text { scenario } \\
(\mathrm{CFR}=1 \%)\end{array}$ & $\begin{array}{c}\text { Scenario } 4 . \\
\text { Estimated } \\
\text { Cases based on } \\
\text { fourth scenario } \\
(\mathrm{CFR}=2 \%)\end{array}$ \\
\hline 1 & Feb 20, 2020 & 2 & 2 & 0 & 100.0 & 4612 & 2767 & 1384 & 692 \\
\hline 2 & Feb 21, 2020 & 5 & 2 & 0 & 40.0 & 4612 & 2767 & 1384 & 692 \\
\hline 3 & Feb 22, 2020 & 18 & 4 & 0 & 22.2 & 9224 & 5534 & 2767 & 1384 \\
\hline 4 & Feb 23, 2020 & 28 & 5 & 0 & 17.9 & 11530 & 6918 & 3459 & 1729 \\
\hline 6 & Feb 25,2020 & 61 & 12 & 0 & 19.7 & 27671 & 16603 & 8301 & 4151 \\
\hline 7 & Feb 26, 2020 & 95 & 15 & 25 & 15.8 & 34589 & 20754 & 10377 & 5188 \\
\hline 8 & Feb 27,2020 & 141 & 22 & 54 & 15.6 & 50731 & 30439 & 15219 & 7610 \\
\hline 9 & Feb 28, 2020 & 245 & 26 & 64 & 10.6 & 59955 & 35973 & 17986 & 8993 \\
\hline 10 & Feb 29,2020 & 388 & 34 & 73 & 8.8 & 78402 & 47041 & 23521 & 11760 \\
\hline 11 & Mar 1, 2020 & 593 & 43 & 123 & 7.3 & 99156 & 59493 & 29747 & 14873 \\
\hline 12 & Mar 2, 2020 & 978 & 54 & 175 & 5.5 & 124521 & 74713 & 37356 & 18678 \\
\hline 13 & Mar 3, 2020 & 1501 & 66 & 291 & 4.4 & 152193 & 91316 & 45658 & 22829 \\
\hline 14 & $\mathrm{Ma} \mathrm{4,} 2020$ & 2339 & 77 & 144 & 3.3 & 177558 & 106535 & 53267 & 26634 \\
\hline 17 & Mar 07, 2020 & 4747 & 124 & 913 & 2.6 & 285938 & 171563 & 85781 & 42891 \\
\hline 18 & Mar 08, 2020 & 5823 & 145 & 1669 & 2.5 & 334362 & 200618 & 100309 & 50154 \\
\hline 19 & Mar 09, 2020 & 6566 & 194 & 2134 & 2.9 & 447354 & 268412 & 134206 & 67103 \\
\hline 20 & Mar 10, 2020 & 7161 & 237 & 2394 & 3.3 & 546510 & 327906 & 163953 & 81976 \\
\hline 21 & Mar 11, 2020 & 8042 & 291 & 2731 & 3.6 & 671031 & 402619 & 201309 & 100655 \\
\hline 22 & Mar 12, 2020 & 9000 & 354 & 2959 & 3.9 & 816306 & 489783 & 244892 & 122446 \\
\hline 23 & Mar 13, 2020 & 10075 & 429 & 3276 & 4.2 & 989252 & 593551 & 296776 & 148388 \\
\hline 24 & Mar 14, 2020 & 11364 & 514 & 3529 & 4.5 & 1185257 & 711154 & 355577 & 177788 \\
\hline 25 & Mar 15, 2020 & 12729 & 611 & 4339 & 4.8 & 1408934 & 845361 & 422680 & 211340 \\
\hline 26 & Mar 16, 2020 & 13938 & 724 & 4590 & 5.1 & 1669506 & 1001704 & 500852 & 250426 \\
\hline 27 & Mar 17, 2020 & 14991 & 853 & 4996 & 5.6 & 1966974 & 1180184 & 590092 & 295046 \\
\hline 28 & Mar 18, 2020 & 16169 & 988 & 5389 & 6.1 & 2278277 & 1366966 & 683483 & 341741 \\
\hline 29 & Mar 19, 2020 & 17361 & 1135 & 5710 & 6.5 & 2617251 & 1570351 & 785175 & 392587 \\
\hline 30 & Mar 20, 2020 & 18407 & 1284 & 5979 & 6.9 & 2960837 & 1776503 & 888251 & 444125 \\
\hline 31 & Mar 21, 2020 & 19644 & 1433 & 6745 & 7.2 & 3304423 & 1982654 & 991327 & 495663 \\
\hline 32 & Mar 22, 2020 & 20610 & 1556 & 7635 & 7.5 & 3588055 & 2152833 & 1076417 & 538208 \\
\hline 33 & Mar 23, 2020 & 21638 & 1685 & 8525 & 7.7 & 3885522 & 2331314 & 1165657 & 582828 \\
\hline 34 & Mar 24, 2020 & 23049 & 1812 & 8625 & 7.8 & 4178378 & 2507027 & 1253513 & 626756 \\
\hline 35 & Mar 25, 2020 & 24811 & 1934 & 9088 & 7.7 & 4459703 & 2675822 & 1337911 & 668955 \\
\hline
\end{tabular}

\section{Discussion}

According to statistics released in Iran, as of March 26, 2020, a total of 27017 people were infected with COVID19, while this number was estimated to be 1436836 (based on $\mathrm{CFR}=1 \%$ ) in the mortality model. According to studies, cases reported in official statistics at the begin- ning of the epidemics are likely to have a severe underestimation of the total of actual cases, so estimating the actual CFR for COVID-19 is currently impossible $(9,10)$. The actual CFR of COVID-19 varies across different regions of the world due to differences in the quality of medical care, socioeconomic factors, immunologic factors, and readiness for the disease $(9,11)$.

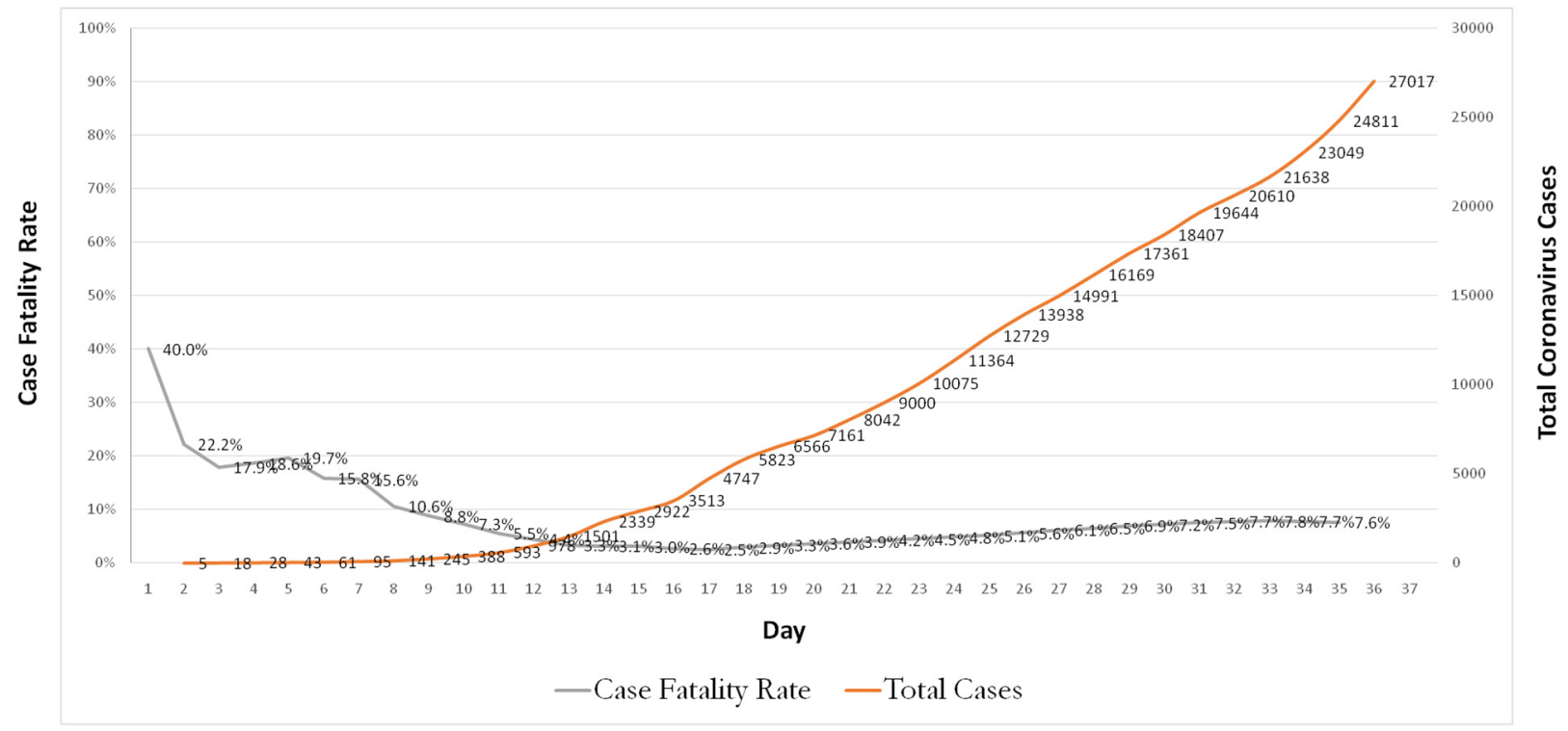

Fig. 1. Confirmed cases and early case fatality rate of COVID-19 in Iran as of March 26, 2020 


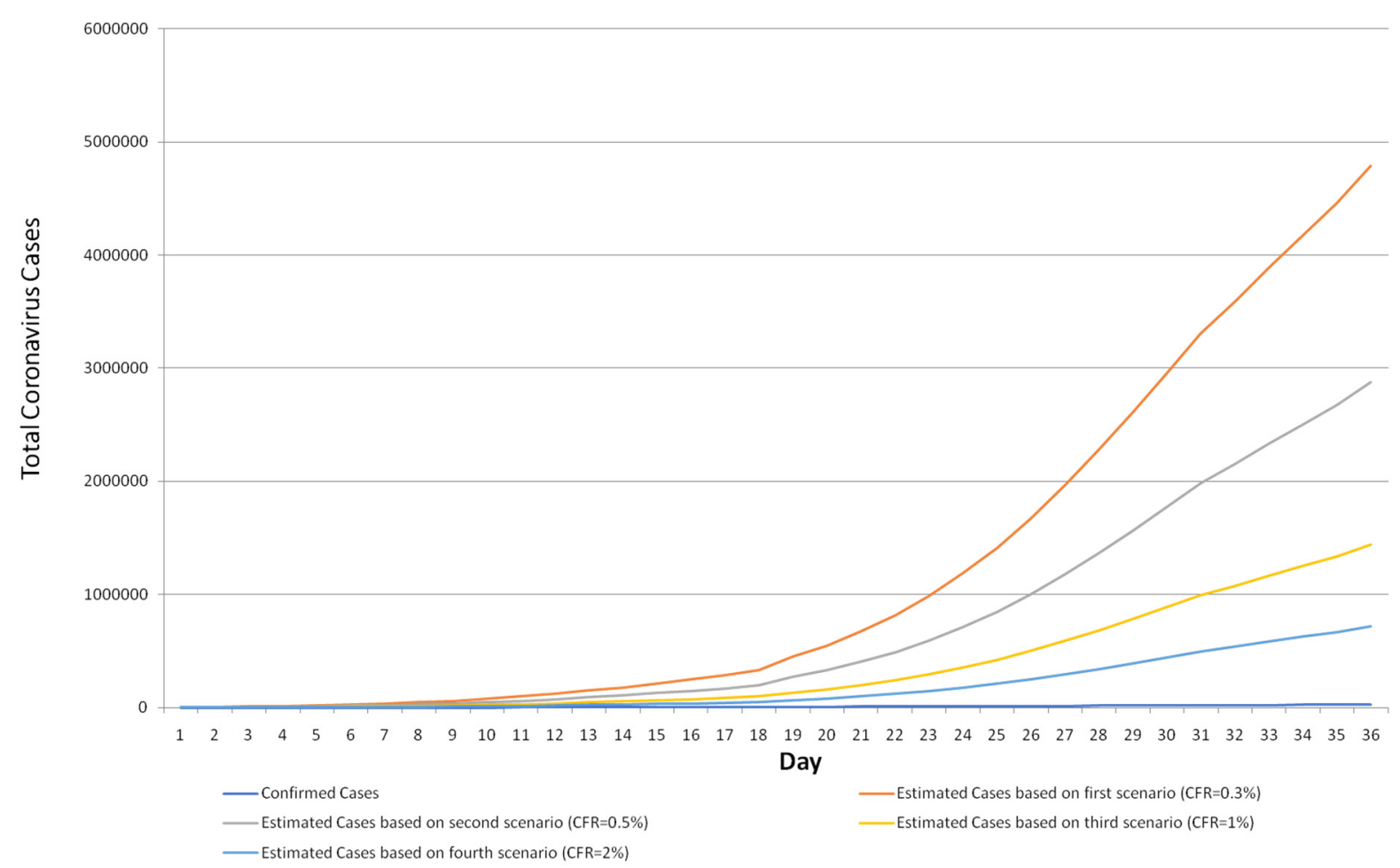

Fig. 2. Confirmed and estimated cases of COVID-19 in Iran as of March 26, 2020

According to the results of this study, by the passage of time since the identification of the first case infected by COVID-19 and increase in the number of positive cases, the indicator of CFR decreases and as the time passes, the amount of this indicator approaches its real amount. To calculate the real amount of CFR indicator, it is necessary to identify all the cases infected by Covid-19 and the total death caused by it. However, currently, only the statistics belonging to those infected patients who refer to medical centers are recorded. The evidences indicate that more than $80 \%$ of people infected by COVID-19 show mild symptoms of the disease (5) and a fraction of this population may not refer to medical centers and, consequently, their data are not recorded. The findings of some studies reveal that the CFR of some emerging diseases such as Ebola decreases over time and this can be the result of creating and increasing the required facilities and infrastructures like laboratories and hospital beds and personnel's enhanced experience (12). On the first days of diagnosis, given the identification of cases most of which led to death, much pressure were on Iran's Health System and different interpretations were put forward regarding this issue. During the outbreak of this epidemic, the main criticism Iran faced was the probability of its inability to identify this virus. One of the other interpretations was that this virus species may be different from the basic species and may be more fatal. These interpretations caused much fear among people and put a great deal of pressure on managers and experts of the Health System for decisionmaking.

Therefore, making decisions just based on the CFR indicator during the outbreak of epidemics may not be the right choice and may result in overestimation and could threaten the mental health of a society. Therefore, more accurate calculation of this indicator requires the passage of time; also, determining CFR needs identification of its natural history. The definition of an appropriate indicator in epidemics is of great significance. In emerging diseases, CFR indicator must be interpreted carefully and its hasty calculation and interpretation can put great pressure on health systems and may lead to making wrong and unprofessional decisions by health care policymakers.

One limitation of this study may be the calculation of the number of patients based on CFR, as it may vary across countries due to differences in hospital services and health infrastructure in each country. Nonetheless, considering that there is no definitive cure for the disease and that the life expectancy of Iranians is near that of the most developed countries, this limitation may not have much impact on the estimations in this study.

\section{Conclusion}

At present, CFR is calculated by dividing the number of known deaths by the number of confirmed cases. The results did not indicate the actual number of deaths. The exact value of CFR in this stage of the epidemic is unknown and its precise estimation is currently impossible. Current estimates of CFR for COVID-19 should also be interpreted with caution as the disease is still unknown. In addition, CFR can be used to estimate the actual number of patients in such situations. Moreover, during the outbreak of epidemics, specifically emerging diseases, judgments should not be based on CFR. It is expected to identify the most emerging epidemics during their outbreak when they are severe and could lead to death. Making judgments based on CFR, specifically in the outbreak of 
emerging epidemics, can lead to information bias. In addition, it seems that CFR decreases after the identification of the first cases and while health systems' ability and awareness gradually increases.

\section{Conflict of Interests}

The authors declare that they have no competing interests.

\section{References}

1. Mahase E. Coronavirus: covid-19 has killed more people than SARS and MERS combined, despite lower case fatality rate. BMJ. 2020;368:m641

2. de Wit E, van Doremalen N, Falzarano D, Munster VJ. SARS and MERS: recent insights into emerging coronaviruses. Nat Rev Microbiol. 2016;14(8):523-34.

3. Hilgenfeld R, Peiris M. From SARS to MERS: 10 years of research on highly pathogenic human coronaviruses. Antiviral Res. 2013 Oct;100(1):286-95.

4. Lai CC, Shih TP, Ko WC, Tang HJ, Hsueh PR. Severe acute respiratory syndrome coronavirus 2 (SARS-CoV-2) and corona virus disease-2019 (COVID-19): the epidemic and the challenges. Int J Antimicrob Agents. 2020 Feb 17:105924.

5. Worldometers. COVID-19 CORONAVIRUS OUTBREAK. World Meters. 2020. [cited 2020 March 14]. Available from: https://www.worldometers.info/coronavirus./

6. MOHME. Ministry of Health and Medical Education. Tehran, Iran. 2020. [cited 2020 March 14]. Available from: air.ir/ZwqjJao.

7. Porcheddu R, Serra C, Kelvin D, Kelvin N, Rubino S. Similarity in Case Fatality Rates (CFR) of COVID-19/SARS-COV-2 in Italy and China. J Infect Dev Ctries. 2020;14(02):125-8.

8. Lu CY, Lee CY, Kao CL, Shao WY, Lee PI, Twu SJ, et al. Incidence and case-fatality rates resulting from the 1998 enterovirus 71 outbreak in Taiwan. J Med Virol. 2002 Jun;67(2):217-23.

9. Battegay M, Kuehl R, Tschudin-Sutter S, Hirsch HH, Widmer AF, Neher RA. 2019-novel Coronavirus (2019-nCoV): estimating the case fatality rate-a word of caution. Swiss Med Wkly. 2020;150(0506).

10. Pueyo T. Coronavirus: Why You Must Act Now. Politicians, community leaders and business leaders: what should you do and when. 2020. Available from: https://medium.com/@tomaspueyo/ coronavirus-act-today-or-people-will-die-f4d3d9cd99ca

11. El Zowalaty ME, Järhult JD. From SARS to COVID-19: A previously unknown SARS-CoV-2 virus of pandemic potential infecting humans-Call for a One Health approach. One Health. 2020:100124.

12. Wang L, Yang G, Jia L, Li Z, Xie J, Li P, et al. Epidemiological features and trends of Ebola virus disease in West Africa. Int J Infect Dis. 2015 Sep;38:52-3. 